\title{
A Mismatch-tolerant RT-LAMP Method for Molecular Diagnosis of Highly Variable Viruses
}

Yingxue $\mathrm{Li}^{1}{ }^{1,2}$, Yi Zhou ${ }^{2}$, Yingying $\mathrm{Ma}^{2}$, Rong $\mathrm{Xu}^{2}$, Xia $\mathrm{Jin}^{3}$ and Chiyu Zhang ${ }^{2}$ *

${ }^{1}$ School of Life Sciences, Shanghai University, Shanghai, China; ${ }^{2}$ Pathogen Discovery and Big Data Center, CAS Key Laboratory of Molecular Virology \& Immunology, Institute Pasteur of Shanghai, Chinese Academy of Sciences, Shanghai, China; ${ }^{3}$ Viral Disease and Vaccine Translational Research Unit, CAS Key Laboratory of Molecular Virology and Immunology, Institute Pasteur of Shanghai, Chinese Academy of Sciences, Shanghai, China

*For correspondence: zhangcy1999@ips.ac.cn

[Abstract] Loop-mediated isothermal amplification (LAMP) has been widely used in the detection of pathogens. However, there are usually numerous variants in one viral pathogen and primers employed in LAMP can hardly match all these variants. The mismatches between the primers and the viral genomes, especially those at the $3^{\prime}$-end of the primers, hinder LAMP reactions, leading to failure of the detection. Here, we present a mismatch-tolerant RT-LAMP protocol, which utilizes the 3'-5' exonuclease activity of the Q5 high-fidelity DNA polymerase to remove potential mismatched bases at the 3'-end of the primers during LAMP amplification. Using HIV-1 as a proof-of-principle, we showed that this protocol could represent a promising tool for accurate detection of genetically unstable viruses in laboratory, hospital and field.

Keywords: Mismatch-tolerant RT-LAMP, Highly variable viruses, Mutant, HIV-1, Visual detection, Highfidelity DNA polymerase

[Background] Emerging and re-emerging infectious diseases are serious threats to global public health (Mehand et al., 2018). Many outbreaks and epidemics have been caused by viruses, such as HIV-1, $\mathrm{HCV}$, MERS-CoV, Ebola virus, A/H7N9 influenza virus, and more recently Zika virus. These viral diseases have led to high morbidity and mortality that disproportionally impacted on low-income countries (Van Doorn, 2017; Fenollar and Mediannikov, 2018; Waldman and Balskus, 2018). Rapid and accurate diagnosis of viral pathogens is crucial for the prevention and control of viral infectious diseases (Mehand et al., 2018).

Isothermal amplification techniques represent a promising direction for the development of point-ofcare testing (POCT) diagnostic tools especially in the low-income countries or resource-limited settings (de Paz et al., 2014). Loop-mediated isothermal amplification (LAMP) is the most widely used isothermal amplification technology in biomedical research (Notomi et al., 2000). Its principle is auto-cycling strand displacement DNA amplification reaction using Bst DNA polymerase with high strand displacement activity under isothermal condition. LAMP generally uses three pairs of primers, and two inner primers (FIP and BIP) are responsible for initiating the self-primed DNA synthesis of the dumbbell form DNA. However, the biggest challenge for the detection of viruses using LAMP is the high genetic diversity of some viral genomes, which exist in the forms of genotypes, subtypes, and/or quasispecies (Sanjuan et 
Please cite this article as: Li et. al., (2019). A Mismatch-tolerant RT-LAMP Method for Molecular Diagnosis of Highly Variable Viruses,Bio-protocol 9 (21): e3415. DOI: 10.21769/BioProtoc.3415.

al., 2010; Domingo and Perales, 2018). These diverse forms can easily cause mismatches with primers during their amplification, thereby resulting in a low sensitivity of detection and a limited spectrum of detection (Zhang et al., 2017; Li et al., 2019; Zhou et al., 2019). It is virtually impossible to detect all variants or serotypes in one LAMP assay as the conserved regions in the genomes are usually too short to completely match the long (approximately $40 \mathrm{nt}$ ) inner primers (FIP and BIP) of the assay. Therefore, an underestimate of viral load or even failure of detection is common using RT-LAMP method, especially for highly variable RNA viruses (Waldman and Balskus, 2018; Zhou et al., 2019). This may be the most important reason that limits the commercial application of LAMP in the diagnosis of viral infectious diseases (Wong et al., 2018). To overcome this problem, we recently developed a mismatch-tolerant RT-LAMP method that contains a minuscule amount of high-fidelity DNA polymerase and utilizes its 3'$5^{\prime}$ exonuclease activity to remove potential mismatched bases at the $3^{\prime}$-end of the primers during amplification (Zhou et al., 2019). The new method was demonstrated to be especially suited for the detection of highly variable viruses (Zhou et al., 2019). In this paper, we provide a detailed protocol of the mismatch-tolerant RT-LAMP method using HIV-1 detection as an example (Table 1).

Table 1. Primers used for the HIV-1 RT-LAMP assay

\begin{tabular}{llll}
\hline Types & Primer & Sequence (5'-3') & Sources \\
\hline Outer primers & AcelN-F3 & CCMMTTTGGAAAGGACCAGC & This work \\
& AcelN-B3b & AACATACATATGRTGYTTTACTA & \\
& AcelN-B3a & TCTTTGAAAYATACATATGRTG & \\
& AcelN-FIPf & CTTGGCACTACYTTTATGTCACTAAARCTYCTCTGGAAAGGTG & (Ocwieja \\
Inner primers & AcelN-FIPe & CTTGGTACTACYTTTATGTCACTAAARCTACTCTGGAAAGGTG & al., \\
& AcelN-BIP & GGAYTATGGAAACAGATGGCAGCCATGTTCTAATCYTCATCCTG & \\
Loop primers & AcelN-LF & TCTTGTATTACTACTGCCCCTT & \\
& AcelN-LB & GTGMTGATTGTGTGGCARGTAG & This work \\
\hline
\end{tabular}

\section{Materials and Reagents}

1. Axygen ${ }^{\circledast}$ MicroVolume Extended-Length Filtered Pipet Tips (Axygen, catalog number: TXLF10)

2. Axygen ${ }^{\circledR}$ Universal Fit $100 \mu$ l Filtered Pipet Tips (Axygen, catalog number: TF100RS)

3. Axygen ${ }^{\circledR}$ Universal Fit $200 \mu$ l Filtered Pipet Tips (Axygen, catalog number: TF200RS)

4. Axygen ${ }^{\circledR}$ Universal Fit $1,000 \mu$ l Filtered Pipet Tips (Axygen, catalog number: TF1000LRS)

5. Axygen $1.5 \mathrm{ml}$ Snaplock Microtubes (Axygen, catalog number: MCT150CS)

6. Axygen $0.2 \mathrm{ml} \mathrm{PCR}^{\circledR}$ Tubes (Axygen, catalog number: PCR02C)

7. LightCycler ${ }^{\circledR} 480$ Multiwell Plate 96,white (Roche, catalog number: 4729692001)

8. LightCycler ${ }^{\circledR}$ 8-Tube Strips, white (Roche, catalog number: 6612601001)

9. DreamTaq ${ }^{\mathrm{TM}}$ Green PCR Master Mix (2x) (Thermo Fisher Scientific, catalog number: k1081)

10. pUC57-IN (containing partial fragment of HIV-1 integrase gene: AF033819.3. the sequen ce is 5'-ACGGTTAGGGCCGCCTGTTGGTGGGCGGGAATCAAGCAGGAATTTGGAATTCCC 
Please cite this article as: Li et. al., (2019). A Mismatch-tolerant RT-LAMP Method for Molecular Diagnosis of Highly Variable Viruses,Bio-protocol 9 (21): e3415. DOI: 10.21769/BioProtoc.3415.

TACAATCCCCAAAGTCAAGGAGTAGTAGAATCTATGAATAAAGAATTAAAGAAAATTATAGGA CAGGTAAGAGATCAGGCTGAACATCTTAAGACAGCAGTACAAATGGCAGTATTCATCCACA ATTTTAAAAGAAAAGGGGGGATTGGGGGGTACAGTGCAGGGGAAAGAATAGTAGACATAA TAGCAACAGACATACAAACTAAAGAATTACAAAAACAAATTACAAAAATTCAAAATTTTCGGG TTTATTACAGGGACAGCAGAAATCCACTTTGGAAAGGACCAGCAAAGCTCCTCTGGAAAG GTGAAGGGGCAGTAGTAATACAAGATAATAGTGACATAAAAGTAGTGCCAAGAAGAAAAGC AAAGATCATTAGGGATTATGGAAAACAGATGGCAGGTGATGATTGTGTGGCAAGTAGACAG GATGAGGATTAGAACATGGAAAAGTTTAGTAAAACACCATATGTATGTTTCAGGGAAAGCTA GGGGATGGTTTTATAGACATCACTATGAAAGCCCTATCGGATCCCGGGCCCGTCGACTG-3') (Synthesized by Shanghai BioSune Biotechnology Co., Ltd.)

11. Qubit ${ }^{T M}$ RNA HS Assay Kit RNA (Life Technologies, catalog number: Q32855)

12. WarmStart RTx Reverse Transcriptase (NEB, catalog number: M0380L)

13. $Q 5^{\circledR}$ High-Fidelity DNA Polymerase (NEB, catalog number: M0491L)

14. Bst 2.0 DNA Polymerase (NEB, catalog number: M0537L)

15. Fast Mutagenesis System (Transgen, catalog number: FM111)

16. QIAgen Viral RNA Mini Kit (Qiagen, catalog number: 52906)

17. QIAquick ${ }^{\circledR}$ Gel Extraction Kit (Qiagen, catalog number: GC-28706)

18. HiScribe T7 High Yield RNA Synthesis Kit (NEB, catalog number: E2040S)

19. WarmStart ${ }^{\circledR}$ Colorimetric LAMP 2x Master Mix (DNA \& RNA) (with cresol red) (NEB, catalog number: M1800S)

20. Isothermal Amplification Buffer Pack (NEB, catalog number: B0537S)

21. Magnesium Sulfate $\left(\mathrm{MgSO}_{4}\right)$ Solution (NEB, catalog number: B1003S)

22. dNTP Set, $100 \mathrm{mM}$ Solutions (Thermo Fisher, catalog number: R0186)

23. SYTO ${ }^{\mathrm{TM}} 9$ Green Fluorescent Nucleic Acid Stain (Invitrogen, catalog number: S34854)

24. Nuclease-Free Water (not DEPC-Treated) (Ambion ${ }^{\mathrm{TM}}$, catalog number: AM9938)

25. Agarose (Biowest, catalog number: BY-R0100)

26. Ultra-pure water (Genview, catalog number: GU3313-500)

27. GelRed Nucleic Acid Straining Dye (10000x) (TOROIVD, catalog number: RSD100-25)

28. Plasma samples (Previous samples from our laboratory)

29. Yeast extract (Oxoid, catalog number: LP0021)

30. Tryptone (Oxoid, catalog number: LP0042)

31. Agar (Shangxiang, catalog number: 120420)

32. Sodium chloride (HuShi, catalog number: 10019318)

33. Ampicillin trihydrate (Solarbio, catalog number: A7490-5)

34. 50x TAE buffer (Meilunbio, catalog number: MA0004)

35. 2000 DNA Marker (Yeasen, catalog number: 10501ES60)

36. 5000 DNA Marker (Yeasen, catalog number: 10504ES60)

37. TIANprep Mini Plasmid Kit (Tiangn, catalog number: DP103-03)

38. Liquid LB medium (see Recipes) 
39. $100 \mathrm{mg} / \mathrm{ml}$ ampicillin solution (see Recipes)

40. Ampicillin-resistant solid medium (see Recipes)

41. Ampicillin-resistant liquid LB medium (see Recipes)

42. $2 \%$ agarose gel (see Recipes)

43. $1 \%$ agarose gel (see Recipes)

\section{Equipment}

1. $0.5-10 \mu \mathrm{l}$ Eppendorf Research ${ }^{\circledR}$ plus Adjustable Volume Pipettes (Eppendorf, catalog number: I32693E)

2. $10-100 \mu$ Eppendorf Research ${ }^{\circledR}$ plus Adjustable Volume Pipettes (Eppendorf, catalog number: 251596Z)

3. 20-200 $\mu$ l Eppendorf Research ${ }^{\circledR}$ plus Adjustable Volume Pipettes (Eppendorf, catalog number: 4830359)

4. $100-1,000 \mu \mathrm{l}$ Eppendorf Research ${ }^{\circledR}$ plus Adjustable Volume Pipettes (Eppendorf, catalog number: 4847859)

5. NanoDrop ${ }^{\mathrm{TM}} 2000$ Spectrophotometer (Thermo Fisher, model: NanoDrop ${ }^{\mathrm{TM}}$ 2000, catalog number: ND-2000)

6. LightCycler ${ }^{\circledR} 96$ System (Roche, catalog number: 05815916001)

7. Bio-Rad CFX96 ${ }^{\mathrm{TM}}$ Real-Time PCR System (Bio-Rad, catalog number: 785BR18555)

8. Eppendorf Centrifuge 5417R (Eppendorf, model: 5417R)

9. Eppendorf Mastercycler nexus (Eppendorf, catalog number:6325ZK904949)

10. Tanon Gel Image System (Tanon, model: 2500)

11. Tanon EPS 300 (Tanon, model: 300 )

12. Tanon electrophoresis tank (Tanon, model: 400)

\section{Software}

1. LightCycler ${ }^{\circledR} 96$ System software (Roche)

2. Bio-Rad CFX Manager 3.1 software (Bio-Rad)

\section{Procedure}

A. Preparation of HIV-1 wild type and mutant RNA standards

1. Construct two mutant pUC57-IN plasmids using the fast mutagenesis system according to the following steps. Primers for construction of the mutant plasmids are in Table 2.

a. Prepare the PCR reaction mixes (Table 3), PCR cycling condition: Enzyme activation and pre-denaturation at $94^{\circ} \mathrm{C}$ for $3 \mathrm{~min}, 25$ cycles of denaturation at $94{ }^{\circ} \mathrm{C}$ for $20 \mathrm{~s}$, annealing at $55{ }^{\circ} \mathrm{C}$ for $20 \mathrm{~s}$ and extension at $72{ }^{\circ} \mathrm{C}$ for $1 \mathrm{~min}$, followed by extending at $72{ }^{\circ} \mathrm{C}$ for 10 
$\min$.

Table 2. Primers for construction of two HIV-1 mutant plasmids

\begin{tabular}{ll}
\hline Primer & Sequence (5'-3') \\
\hline AcelN-F3 Mu1-G F & CTTTGGAAAGGACCAGGAAAGCTCCTC \\
AcelN-F3 Mu1-G R & CCTGGTCCTTTCCAAAGTGGATTTCTG \\
AcelN-F3 Mu2-A F & CTTTGGAAAGGACCAGAAAAGCTCCTC \\
AcelN-F3 Mu2-A R & TCTGGTCCTTTCCAAAGTGGATTTCTG \\
\hline Note: Introduced mutant is shown in Red font. F: forward primer; $R$ : reverse primer; Mu: mutant.
\end{tabular}

Table 3. PCR reaction mixes of the construction of two HIV-1 mutants

\begin{tabular}{ll}
\hline Component & Volume $(\boldsymbol{\mu l})$ \\
\hline pUC57-IN $(1-10 \mathrm{ng})$ & 2 \\
Mu F $(10 \mu \mathrm{M})$ & 1 \\
Mu R $(10 \mu \mathrm{M})$ & 1 \\
$2 \times$ TransStart FastPfu PCR Supermix & 25 \\
Nuclease-free water & 21 \\
total & 50 \\
\hline
\end{tabular}

Note: F: forward primer; R: reverse primer; Mu: mutant.

b. Electrophoresis detection: measure $10 \mu \mathrm{l}$ PCR product using $1 \%$ agarose gel electrophoresis at a constant voltage $(140 \mathrm{~V})$ for about $30 \mathrm{~min}$.

c. PCR product digestion: add $1 \mu \mathrm{l}$ of DMT enzyme to the remaining PCR product, mix and incubate for $1 \mathrm{~h}$ at $37^{\circ} \mathrm{C}$.

d. Add $5 \mu \mathrm{l}$ of DMT digestion product to $50 \mu \mathrm{l}$ of competent cells, mix and place on ice for 30 $\mathrm{min}$. Then place the mixture at $42^{\circ} \mathrm{C}$ for $45 \mathrm{~s}$, and on ice for $2 \mathrm{~min}$.

e. Add $250 \mu \mathrm{l}$ of room temperature LB medium (without antibiotics) to the mixture, $200 \mathrm{rpm}$, $37^{\circ} \mathrm{C}$ for $1 \mathrm{~h}$.

f. Spread $100 \mu \mathrm{l}$ of the bacterial solution evenly on a plate containing $100 \mu \mathrm{g} / \mathrm{ml}$ ampicillin and incubate overnight in a $37^{\circ} \mathrm{C}$ incubator.

g. Pick the mono-clones into $3 \mathrm{ml}$ LB medium containing $100 \mu \mathrm{g} / \mathrm{ml}$ ampicillin, for shaking culture (200 rpm), at $37^{\circ} \mathrm{C}$ for $10-12 \mathrm{~h}$.

h. Extract the plasmid DNA for Sanger sequencing (Shanghai Platinum Company) and verify the presence of the mutation. Store the mutated plasmids at $-20{ }^{\circ} \mathrm{C}$ for subsequent experiments.

2. Amplify the HIV-1 integrase segment using $T 7$ promotor-containing primer pair (HIV T7-F: TAATACGACTCACTATAGACGGTTAGGGCCGCCTGT and HIV R: CAGTCGACGGGCCCGGGA) with the wild-type and mutant HIV-1 plasmids as templates.

a. In a $0.2 \mathrm{ml} \mathrm{PCR}^{\circledR}$ tube with cap, a PCR reaction mix includes $25 \mu \mathrm{l} 2$ DreamTaq $^{\mathrm{TM}}$ Green 
PCR Master Mix, $2 \mu \mathrm{l}$ of $10 \mu \mathrm{M}$ of each primer (HIV T7-F and HIV R primer) and $2 \mu \mathrm{l} \mathrm{HIV-1}$ plasmid in a final volume of $50 \mu$ l.

b. The cycling condition is enzyme activation and pre-denaturation at $95^{\circ} \mathrm{C}$ for $3 \mathrm{~min}$, followed by 40 cycles of denaturation at $95^{\circ} \mathrm{C}$ for $30 \mathrm{~s}$, annealing at $55^{\circ} \mathrm{C}$ for $30 \mathrm{~s}$ and extension at $72{ }^{\circ} \mathrm{C}$ for $1 \mathrm{~min}$, fully extending at $72^{\circ} \mathrm{C}$ for $10 \mathrm{~min}$.

3. Measure the PCR product using $2 \%$ agarose gel electrophoresis at a constant voltage (140 V) for about $30 \mathrm{~min}$.

4. After electrophoresis, cut the specific PCR product from the gel under UV control and purify according to the manufacturer's instruction using the QIAquick ${ }^{\circledR}$ Gel Extraction Kit.

5. Obtain RNAs through in vitro transcription with the purified DNA as templates using the HiScribe T7 High Yield RNA Synthesis Kit.

6. Quantify the obtained RNA using NanoDropTM 2000 Spectrophotometer, and calculate the RNA copy number using the following formula:

RNA copies $/ \mathrm{ml}=[$ RNA concentration $(\mathrm{g} / \mathrm{ml}) /($ nt transcript length $\times 340)] \times 6.022 \times 10^{23}$

7. Dilute RNA to $10^{4}$ copies/ul, aliquot to $40 \mu \mathrm{l}$ in a $0.2 \mathrm{ml} \mathrm{PCR}^{\circledR}$ tube with cap and store at $-80{ }^{\circ} \mathrm{C}$ until use.

B. Plasma sample viral RNA extraction

1. Extract viral RNA from $140 \mu \mathrm{l}$ of plasma using the QIAgen Viral RNA Mini Kit following the manufacturer's instruction.

2. Elute the extracted RNA in $50 \mu \mathrm{l}$ of nuclease-free water, aliquot to $25 \mu \mathrm{l}$ per tube, and store at $80^{\circ} \mathrm{C}$ until use.

C. Qualitative detection of HIV-1 by the real-time mismatch-tolerant HIV-1 RT-LAMP assay

1. Preparation of mixed primer sets (Table 4 )

Prepare the mixed primer set 1 by adding $5 \mu \mathrm{l} 100 \mu \mathrm{m}$ each of primers AcelN-F3, AcelN-B3a, and AcelN-B3b into $85 \mu \mathrm{l}$ nuclease-free water; the mixed primer set 2 includes $20 \mu \mathrm{l} 100 \mu \mathrm{m}$ each of primers AceIN-FIPf and AceIN-FIPe, $40 \mu \mathrm{l} 100 \mu \mathrm{m}$ AceIN-BIP, and $20 \mu \mathrm{l}$ nuclease-free water; the mixed primer set 3 includes $20 \mu \mathrm{l} 100 \mu \mathrm{m}$ each of primers AceIN-LF and AceIN-LB, and $60 \mu \mathrm{l}$ nuclease-free water.

2. Preparation of the real-time RT-LAMP mix (Table 5)

In a 96-well PCR plate or 8-tube PCR strip, each $25 \mu \mathrm{l}$ reaction mix includes $3 \mu \mathrm{l}$ RNA template (RNA standard or RNA extracts from clinical sample), $2.5 \mu \mathrm{l} 10 \mathrm{x}$ isothermal amplification buffer, $1 \mu \mathrm{l} 100 \mathrm{mM} \mathrm{MgSO}_{4}, 3.5 \mu \mathrm{l} 10 \mathrm{mM}$ dNTPs, $0.075 \mu \mathrm{l} 2$ units of Q5 high-fidelity DNA polymerase, $1 \mu \mathrm{l} 8$ units of Bst 2.0 DNA polymerase, $0.5 \mu \mathrm{l} 15$ units of warmstart RTx reverse transcriptase, $1 \mu \mathrm{l} 1 \mathrm{mM}$ SYTO 9, and $1 \mu \mathrm{l}$ each mixed primer set (mixed primer set 1-3 in Table 4). 
Table 4. Mixed primer sets preparation of the mismatch-tolerant RT-LAMP assay

\begin{tabular}{|c|c|c|c|c|}
\hline \multirow[b]{2}{*}{ Mixed primer set } & \multicolumn{2}{|l|}{ HIV-1 RT-LAMP assay } & \multicolumn{2}{|l|}{ Regular LAMP assay } \\
\hline & & Volume $(\mu \mathrm{l})$ & Primers & Volume $(\mu \mathrm{l})$ \\
\hline \multirow{5}{*}{$\begin{array}{l}\text { Mixed primer set } 1 \\
(25 \times)\end{array}$} & $100 \mu \mathrm{M}$ AcelN-F3 & 5 & $100 \mu \mathrm{M} F 3$ & 5 \\
\hline & $100 \mu \mathrm{M}$ AcelN-B3a & 5 & $100 \mu \mathrm{M} \mathrm{B} 3$ & 5 \\
\hline & $100 \mu \mathrm{M}$ AcelN-B3b & 5 & Nuclease-free water & 90 \\
\hline & Nuclease-free water & 85 & & \\
\hline & total & 100 & & 100 \\
\hline \multirow{5}{*}{$\begin{array}{l}\text { Mixed primer set } 2 \\
(25 \times)\end{array}$} & $100 \mu \mathrm{M}$ AcelN-FIPf & 20 & $100 \mu \mathrm{M}$ FIP & 40 \\
\hline & $100 \mu \mathrm{M}$ AcelN-FIPe & 20 & $100 \mu \mathrm{M}$ BIP & 40 \\
\hline & $100 \mu \mathrm{M}$ AceIN-BIP & 40 & Nuclease-free water & 20 \\
\hline & Nuclease-free water & 20 & & \\
\hline & total & 100 & & 100 \\
\hline \multirow{4}{*}{$\begin{array}{l}\text { Mixed primer set } 3 \\
(25 \times)\end{array}$} & $100 \mu \mathrm{M}$ AcelN-LF & 20 & $100 \mu \mathrm{M}$ Loop F & 20 \\
\hline & $100 \mu \mathrm{M}$ AcelN-LB & 20 & $100 \mu \mathrm{M}$ Loop B & 20 \\
\hline & Nuclease-free water & 60 & Nuclease-free water & 60 \\
\hline & total & 100 & total & 100 \\
\hline
\end{tabular}

Note: The regular assay is recommended when no degenerate primers is used.

3. RT-LAMP cycling condition: Perform the reaction at $62{ }^{\circ} \mathrm{C}$ for 1 min by 60 cycles. Collect fluorescence signal at each cycle.

D. Colorimetric RT-LAMP detection (Table 5)

1. Preparation of the colorimetric RT-LAMP mix (Table 5)

In an 8-tube PCR strip, each $25 \mu$ reaction mix includes $12.5 \mu$ l warmstart colorimetric LAMP $2 x$ master mix, $1 \mu \mathrm{l}$ each mixed primer set (mixed primer sets 1-3 in Table 4), $0.075 \mu \mathrm{l} 2$ units of Q5 high-fidelity DNA polymerase, and $3 \mu$ of RNA template (RNA standard or RNA extracts from clinical sample).

2. Colorimetric RT-LAMP cycling condition: Perform the reaction at $62{ }^{\circ} \mathrm{C}$ for $50 \mathrm{~min}$. Observe the color change at 20-, 30-, 40-, and 50-min time points by naked eyes.

\section{Data analysis}

1. The result of the real-time mismatch-tolerant RT-LAMP assay can be seen with LightCycler ${ }^{\circledR} 96$ system software, Bio-Rad CFX manager 3.1 software (Figure 1) or softwares implemented in other real-time PCR machines. Positive results (with the presence of HIV-1 templates) show clear "S" type amplification curves, and negative results (without HIV-1 template) have no amplification curve. The $\mathrm{Ct}$ values (time to appearance of the amplification curve) are negatively 
related to the amount of template input.

\section{A Light Cycler ${ }^{\circledR} 96$ System}

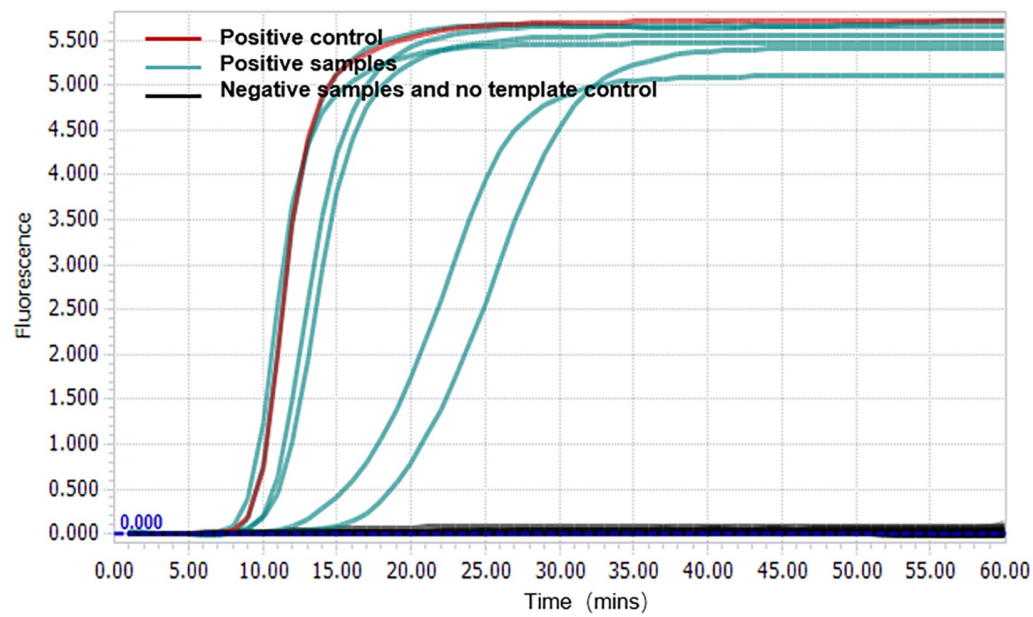

B Bio-Rad CFX 96 TM Real-Time PCR System

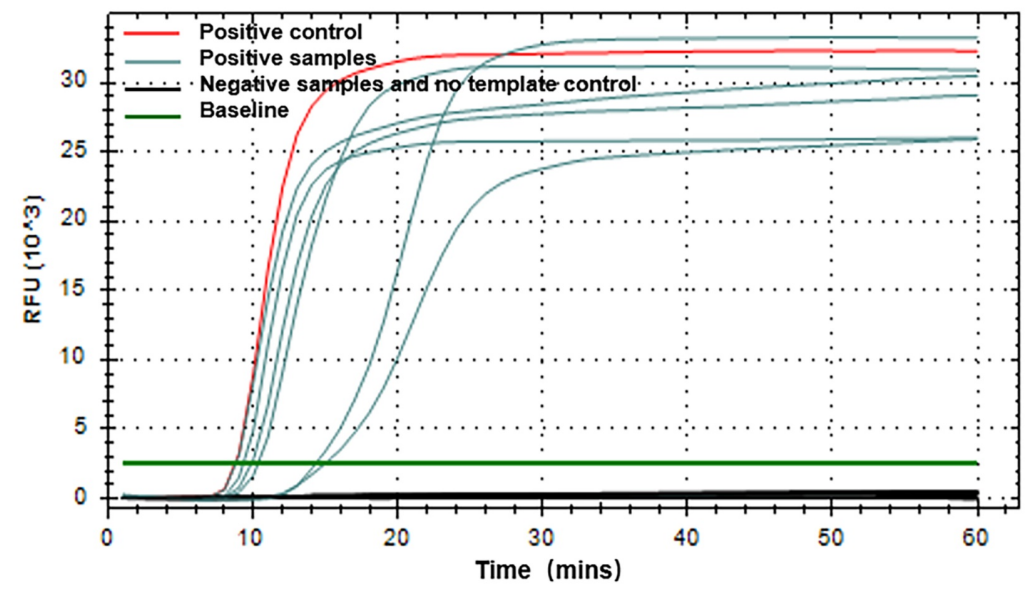

Figure 1. Amplification curves of the real-time mismatch-tolerant HIV-1 RT-LAMP. Amplification curves using LightCycler ${ }^{\circledR} 96$ system (A) or Bio-Rad CFX96 TM Real-Time PCR system (B). HIV-1 RNA standard used as a positive control is shown in red, clinical samples from HIV-positive subjects are shown in cyan, and samples from HIV-negative subjects or that do not have template are shown in black.

2. In the Colorimetric RT-LAMP detection assay, the results can be judged by naked eyes. A clear color change from burgundy to orange or yellow is considered as HIV-1 positive at 30-50 min which is dependent on the set cut-off (Figure 2). 
Table 5. Real-time and colorimetric reaction mixes of the mismatch-tolerant RT-LAMP assay

\begin{tabular}{|c|c|c|}
\hline Component & $\begin{array}{l}\text { Real-time RT-LAMP } \\
(\mu \mathrm{l})\end{array}$ & $\begin{array}{l}\text { Colorimetric RT-LAMP } \\
(\mu \mathrm{l})\end{array}$ \\
\hline 10× Isothermal Amplification Buffer & 2.5 & - \\
\hline WarmStart Colorimetric LAMP 2x Master Mix & - & 12.5 \\
\hline $\mathrm{MgSO}_{4}(100 \mathrm{mM})$ & 1 & - \\
\hline dNTPs (10 mM) & 3.5 & - \\
\hline Bst 2.0 DNA polymerase (8 U) & 1 & - \\
\hline Warmstart RTx reverse transcriptase (15 U) & 0.5 & - \\
\hline Q5 high-fidelity DNA polymerase $(0.2 \mathrm{U} / \mu \mathrm{l})$ & 0.75 & 0.75 \\
\hline SYTO $9(1 \times)$ & 1 & - \\
\hline Mixed primer set $1(25 \times)$ & 1 & 1 \\
\hline Mixed primer set $2(25 \times)$ & 1 & 1 \\
\hline Mixed primer set $3(25 \times)$ & 1 & 1 \\
\hline RNA template & 3 & 3 \\
\hline Nuclease-free water & 8.75 & 5.75 \\
\hline Total & 25 & 25 \\
\hline
\end{tabular}

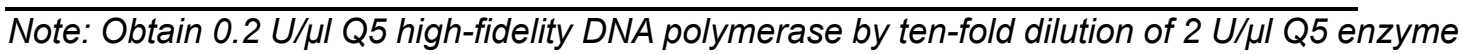
stock.

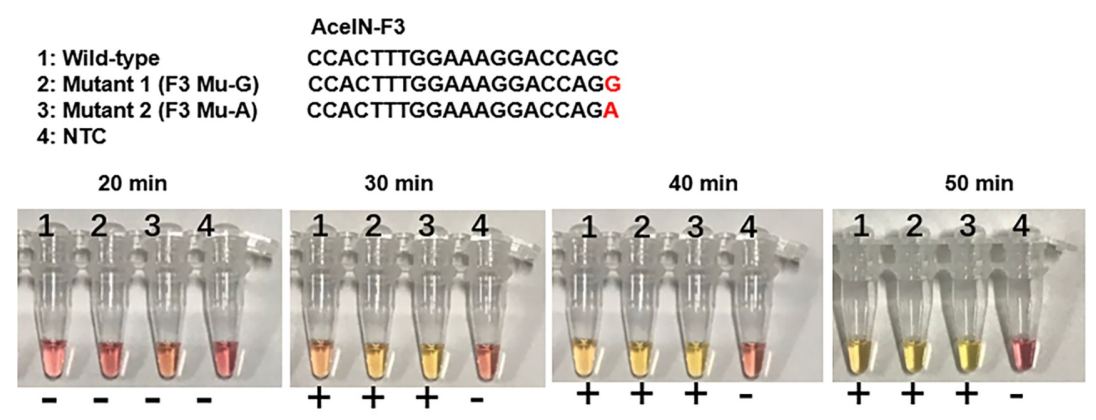

Figure 2. Colorimetric RT-LAMP detection of HIV-1. The color change from burgundy to orange or yellow is considered as positive (+). NTC: no template control. The mutated base is marked in red. AcelN-F3 is an outer forward primer.

\section{$\underline{\text { Notes }}$}

1. The LAMP reaction is very sensitive. Attention should be paid to avoid contamination during the operation, and a stringent laboratory compartmentalization is strongly recommended for LAMP and other amplification assays.

2. To avoid potential contamination, agarose gel electrophoresis of LAMP products is not 
encouraged.

3. Because only a small amount of Q5 high-fidelity DNA polymerase is used in each reaction, the enzyme stock can be diluted to a lower concentration (e.g., $0.2 \mathrm{U} / \mu \mathrm{l})$ to reduce pipetting error.

4. Other high-fidelity DNA polymerases can also be used instead of Q5 enzyme in the reaction. The recommended optimal concentration of high-fidelity DNA polymerase is between 0.1 and 0.3 units per $25 \mu \mathrm{l}$ LAMP reaction.

5. The exact amount of Q5 high-fidelity DNA polymerase per $25 \mu$ LAMP reaction needs to be optimized for detection of each specific virus.

6. If there are no degenerate primers to be used, the primer mix can be prepared based on the standard assay (Table 2).

7. The amount of RNA template per $25 \mu \mathrm{L}$ LAMP reaction can be adjusted between the range of 0 $11.75 \mu \mathrm{l}$ for the real-time version, and 0-8.75 $\mu \mathrm{l}$ for the colorimetric version (Table 3).

\section{$\underline{\text { Recipes }}$}

1. Liquid LB medium

$10 \mathrm{~g}$ of tryptone $5 \mathrm{~g}$ of yeast extract and $10 \mathrm{~g}$ of sodium chloride in $1 \mathrm{~L}$ of ultra-pure water

Mix and autoclave it

2. $100 \mathrm{mg} / \mathrm{ml}$ ampicillin solution

$1 \mathrm{~g}$ of ampicillin powder in $5 \mathrm{ml}$ of ultra-pure water

After it was dissolved, add ultra-pure water to make it to $10 \mathrm{ml}$

Dispense the $100 \mathrm{mg} / \mathrm{ml}$ ampicillin solution into a $1.5 \mathrm{ml} \mathrm{EP}$ tube and store at $-20^{\circ} \mathrm{C}$ until use

3. Ampicillin-resistant solid medium

$10 \mathrm{~g}$ of tryptone, $5 \mathrm{~g}$ of yeast extract, $10 \mathrm{~g}$ of sodium chloride and $15 \mathrm{~g}$ of agar in $1 \mathrm{~L}$ of ultrapure water

Mix and autoclave it

Add $1 \mathrm{ml}$ of $100 \mathrm{mg} / \mathrm{ml}$ ampicillin solution and mix it

Pour about $10 \mathrm{ml}$ on each plate, and store at $4{ }^{\circ} \mathrm{C}$ after solidification

4. Ampicillin-resistant liquid LB medium

Add $50 \mu \mathrm{l}$ of $100 \mathrm{mg} / \mathrm{ml}$ ampicillin solution in $50 \mathrm{ml}$ liquid LB medium and mix it

5. $2 \%$ agarose gel

$2 \mathrm{~g}$ of agarose in $100 \mathrm{ml}$ of $1 \mathrm{x}$ TAE and $10 \mu \mathrm{l} 10000 \mathrm{x}$ GelRed

6. $1 \%$ agarose gel

$1 \mathrm{~g}$ of agarose in $100 \mathrm{ml}$ of $1 \mathrm{x}$ TAE and $10 \mu \mathrm{l} 10000 \mathrm{x}$ GelRed 


\section{Acknowledgments}

This protocol was modified from our original method published previously (Zhou et al., 2019). This study was supported by grants from the National Natural Science Foundation of China (81672033 and U1302224), the National Science and Technology Major Project of China (2017ZX10103009002), the "One Belt One Road" Project (153831KYSB20170043) of Chinese Academy of Sciences, and the 133 projects of Institute Pasteur of Shanghai, CAS. The funders had no role in study design, data collection and analysis, decision to publish, or preparation of the manuscript.

\section{Competing interests}

The authors declare no competing interests.

\section{$\underline{\text { References }}$}

1. de Paz, H. D., Brotons, P. and Muñoz-Almagro, C. (2014). Molecular isothermal techniques for combating infectious diseases: towards low-cost point-of-care diagnostics. Expert Rev Mol Diagn 14(7): 827-843.

2. Domingo, E. and Perales, C. (2018). Quasispecies and virus. Eur Biophys J 47(4): 443-457.

3. Fenollar, F. and Mediannikov, O. (2018). Emerging infectious diseases in Africa in the 21st century. New Microbes New Infect 26: S10-S18.

4. Li, Y., Wan, Z., Hu, Y., Zhou, Y., Chen, Q. and Zhang, C. (2019). A mismatch-tolerant RTquantitative PCR: application to broad-spectrum detection of respiratory syncytial virus. Biotechniques 66(5): 225-230.

5. Mehand, M. S., Al-Shorbaji, F., Millett, P. and Murgue, B. (2018). The WHO R\&D Blueprint: 2018 review of emerging infectious diseases requiring urgent research and development efforts. Antiviral Res 159: 63-67.

6. Notomi, T., Okayama, H., Masubuchi, H., Yonekawa, T., Watanabe, K., Amino, N. and Hase, T. (2000). Loop-mediated isothermal amplification of DNA. Nucleic Acids Res 28(12): E63.

7. Ocwieja, K. E., Sherrill-Mix, S., Liu, C., Song, J., Bau, H. and Bushman, F. D. (2015). A reverse transcription loop-mediated isothermal amplification assay optimized to detect multiple HIV subtypes. PLoS One 10(2): e0117852.

8. Sanjuan, R., Nebot, M. R., Chirico, N., Mansky, L. M. and Belshaw, R. (2010). Viral mutation rates. J Virol 84(19): 9733-9748.

9. Van Doorn, H. R. (2017). Emerging infectious diseases. Medicine 45: 798-801.

10. Waldman, A. J. and Balskus, E. P. (2018). The human microbiota, infectious disease, and global health: challenges and opportunities. ACS Infect Dis 4(1): 14-26.

11. Wong, Y. P., Othman, S., Lau, Y. L., Radu, S., and Chee, H. Y. (2018). Loop-mediated isothermal amplification (LAMP): a versatile technique for detection of micro-organisms. J Appl Microbiol 
124(3): 626-643.

12. Zhang, M., Liu, K., Hu, Y., Lin, Y., Li, Y., Zhong, P., Jin, X., Zhu, X. and Zhang, C. (2017). $\underline{A}$ novel quantitative PCR mediated by high-fidelity DNA polymerase. Sci Rep 7(1): 10365.

13. Zhou, Y., Wan, Z., Yang, S., Li, Y., Li, M., Wang, B., Hu, Y., Xia, X., Jin, X., Yu, N. and Zhang, C. (2019). A mismatch-tolerant reverse transcription loop-mediated isothermal amplification method and its application on simultaneous detection of all four serotype of dengue viruses. Front Microbiol 10: 1056. 